động, vẫn mang tâm lí nghỉ ngơi hồi phục sức khỏe, chưa dám vận động sinh hoạt đi lại bình thường. Tuy nhiên theo thời gian, người bệnh hồi phục và điểm được cải thiện rõ rệt sau 3 và 6 tháng.

Về lĩnh vực tinh thần, điểm có cải thiên nhưng không nhiều. Điểm không cải thiện nhiều do điểm MCS trước can thiệp cấy máy của bệnh nhân cũng khá cao.

Can thiệp cây máy tạo nhịp vĩnh viễn là có hiệu quả làm tăng CLCS của người bệnh đo bằng thang SF-12 từ mức thấp lên mức khá cao. Điều này chứng tỏ bên cạnh sức khỏe tinh thần, việc hồi phục sức khỏe và các bênh lí nhịp tim cải thiện đã đem lại CLCS cho người bệnh tốt hơn rất nhiều.

\section{KẾT LUÂN}

Chất lượng cuộc sống theo thang điểm AQUAREL và SF-12 sau cây máy 1 tháng, 3 tháng và 6 tháng cho thấy sự cải thiện về đa số các khía cạnh ngoại trừ khía cạnh sức khỏe tinh thần. Nhìn chung cãy máy tạo nhịp vĩnh viễn điều trị rối loạn nhịp chậm cho thấy hiệu quả sớm trong cải thiện chất lượng cuộc sống.

\section{TÀI LIÊU THAM KHẢO}

1. Phạm Như Hùng, Trân Song Giang và công sư. "Thức trang cấy máy tao nhip 1 buồng và 2 buiông tim trong điêu trị nhị̣ chậm tại Viện tim mach Việt Nam". Tạp chí tim mạch học Việt Nam số 65, 64்-69 tạo nhịp tim. Luận văn tiển sĩ Ỳ khoa: Hoc viên quân Y 103.2005.

2. Trương Đắc Cường. Nghiên cứu sự thay đổi chất lượng cuộc sống của bênh nhân rối loan nhịp châm trước và sau cây máy tạo nhịp tim vĩnh viến. Đề tài tốt nghiêpp Trường đại hơc Y Hà Nội năm 2014.

3. Đố Thị Diệu Linh (2015), Chất lượng cuộc sống của bểnh nhhân rối loạn nhip tim sau cấy máy tao nhip tim vĩnh viến năm 2015. Đề tài tốt nghiếp cử nhẩn điều dưỡng, trường Đại học Thăng Long.

4. Mond HG, Proclemer A (201i). " the 11th world survery of cảdiac pacing and implantable cardioverter - defibrillators: calendả year 2009 - a World society of Arrhythmia's project". Pacing Clin Electrophysiol, 34(8), 1013 - 1027.

5. Fleischmann K.E, Orav E.J, Lamas G.A, et al (2006). "Pacemaker implantation and quality of life in the Mode Selection Trial (MOST)". Heart rhythm, 3(6), $653-659$.

6. Barros R T d, Carvalho S M R d, Silva M A d M, et al (2014). "Evaluation of patients' quality of life aspects after cardiac pacemaker implantation". Brazilian Journal of Cardiovascular Surgery, 29 (1), 37-44.

7. Udo E.O, van Hemel $\mathbf{N}$ M, Zuithoff $\mathbf{N} P$, et al (2013). "Long tem quality - of - life in patients with bradycardia pacemaker implantation". Internationnal Journal of cardiology, 168 (3), $2159-2163$.

8. Stofmeel M.A, Post W, Kelder JC, et al (2001). "Changes in quality - of - life after pacermaker implantation: Responsiveness of the Aquarel questionnaire". Pacing and Clinical Electrophysiology, 24 (3), 288

\title{
ĐÁNH GIÁ HIÊU QUẢ CỦA NEOSTIGMIN VÀ ATROPIN ĐỂ ĐIỀU TRI ĐAU ĐẦU SAU GÂY TÊ TỦY SỐNG HOĂC GÂY TÊ NGOÀI MÀNG CỨNG TRONG SẢN KHOA
}

\author{
Lương Thị Hoài Khanh', Nguyễn Duy Ánh' ${ }^{2}$, Nguyễn Đức $\mathrm{Lam}^{3}$
}

\section{TÓM TẮT'³}

Mục tiêu: Đánh giá hiệu quả của Neostigmin và Atropin để điều trị đau đâu sau gây tê tủy sống hoặc gây tê ngoài màng cứng trong sản khoa. 60 sản phụ đau đầu sau gây tê tủy sống hoặc gây tê ngoài màñ cứng, đủ tiêu chuẩn lựa chọn được phân bố ngẫu nhiên để điêu trị bằng Neostigmin $20 \mathrm{mcg} / \mathrm{kg}$ và Atropin $10 \mathrm{mcg} / \mathrm{kg}$ hoặc Paracetamol $1 \mathrm{~g}$. Kết quá cho thây điểm VAS trung bình khi bênh nhân ngồi thẳng 15 phút khác biệt có ý nghĩa thống kê giữa 2 nhóm ( $\mathrm{p}$

${ }^{1}$ Bệnh viện Sản nhi Nghê An,

Bênh viện Phu sản Hà Nội,

${ }^{3}$ Đai hoc Y Hà Nôi

Chịu trách nhiệm chính: Lương Thị Hoài Khanh

Email: luonghoaikhanh.bsch@gmail.com

Ngày nhân bài: 2.7.2021

Ngày phản biên khoa hoc: 27.8.2021

Ngày duyệt bài: 3.9.2021
$<0,05)$ ở các thời điểm sau tiêm thuốc 6 giờ, 12 giờ, 24 giờ, 36 giờ, 48 giờ, 72 giờ. Nhóm Neostigmin + Atropin không có bệnh nhân nào cần làm thủ thuật vá máu ngoài màng cứng trong khi nhóm Paracetamol có 6 bệnh nhân $(p<0,05)$.

Tư khóa: đau đầu sau gây tê tủy sống, đau đầu sau gây tê ngoài màng cứng, Neostigmin, Atropin).

\section{SUMMARY}

ASSESSMENT OF EFFECTIVENESS OF NEOSTIGMINE AND ATROPINE FOR THE TREATMENT OF HEADACHE AFTER SPINAL OR EPIDURAL ANAESTHESIA IN OBSTETRIC

The objective: To evaluate the efficacy of Neostigmine and Atropine for the treatment of headache after spinal or epidural anaesthesia in obstetrics. Sixty women havingheadache after spinal or epidural anesthesia, eligible for research, were randomly selected to receive treatment with Neostigmine $20 \mathrm{mcg} / \mathrm{kg}+$ Atropine $10 \mathrm{mcg} / \mathrm{kg}$ or 
Paracetamol 1g. The results showed that the average VAS Score when the patient sat upright for 15 minutes is statistically significant different between the 2 groups $(p<0.05)$ at the time of injection 6 hours, 12 hours, 24 hours, 36 hours, 48 hours, 72 hours after injection. In the Neostigmine and Atropine group, no patient needed an epidural blood patch while in the Paracetamol group there were 6 patients $(p<0.05)$.

Keywords; headache after spinal anesthesia, epidural anesthesia, Neostigmine, Atropine).

\section{I. ĐẶT VẤN ĐỀ}

Gây tê tủy sống (GTTS) và gây tê ngoài màng cứng (GT NMC) ngày càng được hoàn thiện và áp dụng rộng rãi, hiệu quả trong sản khoa. Trong đó, gây tê tủy sống sử dụng để vô cảm trong mổ lấy thai còn gây tê ngoài màng cứng lại được sử dụng để giảm đau trong chuyển da và giảm đau sau mổ lấy thai. Đau đầu là một trong những biến chứng khá hay gặp của GTTS và GT NMC với tỷ lệ thay đổi từ 1,6 đến $30 \%$. Đau đầu gây hạn chế trong việc chăm sóc sơ sinh, kéo dài thời gian nằm viện, có thể tiến triển thành đau đầu mãn tính và có thể gây ra trầm cảm sau sinh. [1] Do đó, xử trí đau đầu sau gây tê tủy sống và gây tê ngoài màng cứng ngày càng được quan tâm nghiên cứu nhiêu hơn. Đau đâu sau gây tê tủy sống và gây tê ngoài màng cứng là do kim gây tê chọc thủng màng cứng và màng nhện gây thoát dịch não tủy ra khoang ngoài màng cứng làm giảm áp lực dịch não tủy gây mất cân bằng giữa áp lực động mạch và áp lực nội sọ dẫn đến tăng áp lực tưới máu do đó gây phù não. [2], [3] Trên thế giới đã có nhiều nghiên cứu về đau đầu sau GTTS hoặc GTNMC [2], [3], [4], đặc biệt, các nghiên cứu gần đây cho thấy Neostigmin phối hợp Atropin [5] cho hiệu quả rất tốt. Tại Việt Nam chưa có nghiên cứu nào về hiệu quả điều trị đau đầu sau GTTS hoặc GT NMC của hai thuốc này. Vì vậy, chúng tôi thực hiện đề tài này nhằm mục tiêu đánh giá hiệu quả của Neostigmin+Atropin để điều trị đau đầu sau GTTS hoặc GT NMC trong sản khoa.

\section{II. ĐỐI TƯợNG VÀ PHƯƠNG PHÁP NGHIÊN CỨU 1. Đối tượng}

Tiêu chuẩn lựa chọn: Sản phụ tuổi 20 - 40, ASA II, đồng ý tham gia nghiên cứu này, được chẩn đoán đau đầu sau gây tê tủy sống hoặc gây tê ngoài màng cứng theo tiêu chí của Hiệp hội đau đầu Quốc tế, VAS $\geq 4$.

Tiêu chuấn loại trừ: Sản phụ đau đầu sau GTTS và GT NMC nhưng điểm VAS < 4 , tiền sử đau đầu mãn tính, đau nửa đầu, co giật, tai biến mạch máu não, có dấu hiệu màng não, tiền sản giật, sản giật, mắc bệnh lý thần kinh trước đó, chảy máu nghiêm trọng $\geq 20 \%$ thể tích máu, trải qua điều trị với thuốc vận mạch, hen phế quản, rối loạn nhịp tim, bệnh tim mạch, bệnh nhân có biến chứng phẫu thuật, bất kì chống chì định của thuốc.

\section{Phương pháp}

Thiết kế nghiên cứu: Nghiên cứu thử nghiệm lâm sàng, ngẫu nhiên có đối chứng.

Địa điểm, thời gian nghiên cứu: Khoa sản thường, khoa sản bệnh, khoa đẻ tự nguyện, khoa mổ tự nguyện, Bệnh viện phụ sản Hà Nội, từ tháng 7 năm 2020 đến tháng 7 năm 2021.

Cõ̃ mẫu: 60 bệnh nhân chia đều làm 2 nhóm, nhóm $\mathrm{N}$ điều trị bằng Neostigmin+Atropin, nhóm $\mathrm{P}$ điều trị bằng Paracetamol.

Chọn mẫu: Chọn mẫu bằng bốc thăm ngẫu nhiên. Nhóm N, 30 bệnh nhân, sử dụng 20 $\mathrm{mcg} / \mathrm{kg}$ Neostigmin và $10 \mathrm{mcg} / \mathrm{kg}$ Atropin trong $20 \mathrm{ml}$ dung dịch muối $0,9 \%$. Nhóm $P, 30$ bênh nhân, sử dưng Paracetamol $1 \mathrm{~g}$ truyền tĩnh mạch.

Các bước tiến hành: Với tất cả bệnh nhân nghiên cứu, tiến hành điều trị nền: Tư thế nằm ngửa, truyền dịch liên tục $30 \mathrm{ml} / \mathrm{kg} / \mathrm{ngày}$ dung dịch Ringerlaclat, tốc độ 60 giọt/phút.

Nhóm N: Tiêm tĩnh mạch chậm $20 \mathrm{mcg} / \mathrm{kg}$ Neostigmin và $10 \mathrm{mcg} / \mathrm{kg}$ Atropin trong $20 \mathrm{ml}$ dung dịch muối 0,9\% trong 5 phút mỗi 8 giờ cho đến khi VAS $\leq 3$.

Nhóm P: Truyền Paracetamol $1 \mathrm{~g}$ trong 15 phút mỗi 8 giờ cho đến khi VAS $\leq 3$.

Bênh nhân không đáp ứng với điều trị trong vòng 48 giờ, có thể được điều trị bằng thủ thuật vá máu ngoài màng cứng.

Các tiêu chí đánh giá: tuổi, BMI, thời gian khởi phát đau đầu, tỷ lệ đau cố gáy trước điều tri, nôn và buồn nôn trước điều tri. Các tiêu chí đánh giá hiệu quả của Neostigmin+Atropin để điều trị đau đâu sau GTTS hoặc GT NMC trong sản khoa: Điểm VAS sau khi bệnh nhân ngồi thẳng 15 phút, cần vá máu ngoài màng cứng, đau cổ gáy sau điêu trị 48 giờ, nôn và buồn nôn sau điều trị 48 giờ, số ngày nằm viện, độ hài lòng của bệnh nhân.

\section{KẾT QUẢ NGHIÊN CỨU}

\section{Một số đặc điểm chung của đối tượng} nghiên cứu:

Tuổi, BMI, thời gian khởi phát đau đầu

Bảng 1. Tuôii, BMI, thời gian khởi phát đau đầu

\begin{tabular}{|c|c|c|c|c|}
\hline & Nhóm & $\begin{array}{c}N \\
(0,=30)\end{array}$ & $\stackrel{\mathrm{P}}{(20)}$ & p \\
\hline & & & $\frac{\left(\mathbf{n}_{\mathbf{2}}=3 \mathrm{U}\right)}{3050+}$ & \\
\hline Tuôi & SD & $\begin{array}{c}2,11 \\
4,05\end{array}$ & $\begin{array}{c}30,31 \\
4,31\end{array}$ & $>0,05$ \\
\hline
\end{tabular}


VIETNAM MEDICAL JOURNAL N¹ - OCTOBER - 2021

\begin{tabular}{|c|c|c|c|c|}
\hline BMI & $\begin{array}{c}\overline{\mathrm{X}} \pm \\
\mathrm{SD}\end{array}$ & $\begin{array}{c}24,25 \pm \\
1,70\end{array}$ & $\begin{array}{c}23,92 \pm \\
1,50\end{array}$ & $>0,05$ \\
\hline $\begin{array}{c}\text { Thời gian } \\
\text { khởi phát } \\
\text { đau đâu }\end{array}$ & $\begin{array}{c}\overline{\mathrm{X}} \pm \\
\mathrm{SD}\end{array}$ & $\begin{array}{c}2,27 \pm \\
0,45\end{array}$ & $2,17 \pm 0,38$ & $>0,05$ \\
\hline
\end{tabular}

Nhân xét: Sự khác biệt về các chỉ số tuối, BMI, thời gian khởi phát đảau đâu giữa 2 nhóm không có ý nghĩa thống kê.

Đau cố gáy, nôn và buồn nôn trước điều trị

Bảng 2. Tý lề đau cồ gáy, nôn và buônn nôn trước điếu trị

\begin{tabular}{|c|c|c|c|c|}
\hline \multicolumn{2}{|c|}{ Nhóm } & $\mathbf{N}$ & $\mathbf{P}$ & $\mathbf{p}$ \\
\hline Đặc điếm & $\left(\mathbf{n}_{\mathbf{1}}=\mathbf{3 0}\right)$ & $\begin{array}{c}\mathbf{P}=\mathbf{3 0}) \\
\left(\mathbf{n}_{\mathbf{2}}=\mathbf{3 0}\right)\end{array}$ & $\mathbf{p}$ \\
\hline $\begin{array}{c}\text { Nôn vồ gáy buồn } \\
\text { nôn }\end{array}$ & $\%$ & 33,3 & 43,3 & $>0,05$ \\
\hline
\end{tabular}

Nhân xét: Sư khác biêt về các chỉ số đau cổ gáy, nồn và buồn nôn giữa 2 nhóm không có ý nghĩa thống kê.

2. Hiệu quả giảm đau:

Điểm VAS tại các thời điểm nghiên cứu:

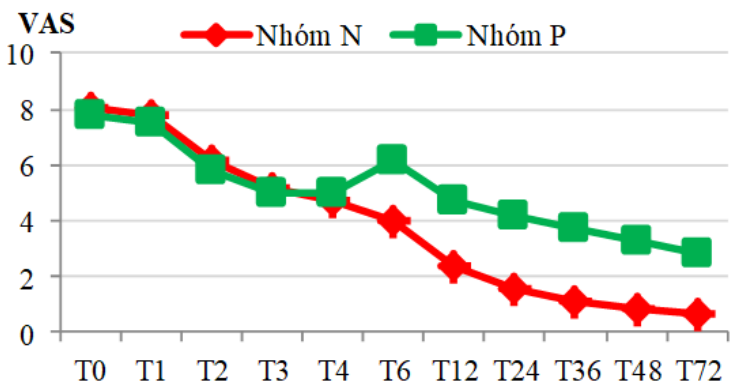

Biểu đồ 1. Điểm VAS tại các thởi điểm nghiên cứu

Nhânn xét: Điểm VAS trung bình khi bệnh nhân ngôi thẳng 15 phút khác biệt có ý nghĩa thống kê giữa 2 nhóm $(p<0,05)$ ở các thời điểm sau tiêm 6 giờ, 12 giờ, 24 giờ, 36 giờ, 48 giờ, 72 giờ. Điểm VAS trung bình khi bệnh nhân ngồi thẳng 15 phút ở nhóm $\mathrm{N}$ đạt giá trị $\leq 3$ ở thời điểm 12 giờ sau tiêm, sớm hơn so với ở nhóm $\mathrm{P}$ là 48 giờ sau tiêm.

Tỷ lệ bệnh nhân cân vá máu ngoài màng cứng sau 48 giờ: Ở nhóm $\mathrm{N}$, không có bệnh nhân nào cân làm thủ thuật vá máu ngoài màng cứng. Ở nhóm $P$, có 6 bểnh nhân cân làm thủ thuật vá máu ngoài màng cứng, chiếm tỷ lệ $20 \%$. Sự khác biệt này có ý nghĩa thống kế $(p<0,05)$. Đau cổ gáy, nôn và buôn nôn sau điều trị 48 giờ

Bảng 3. Tỷ lệ đau cổ gáy, nôn và buôn nôn sau điêu trị 48 giờ

\begin{tabular}{|l|c|c|c|}
\hline Đặc điểm Nhóm & $\underset{N}{N}$ & $\begin{array}{c}P \\
\left(n_{1}=30\right)\end{array}$ & $p$ \\
\hline
\end{tabular}

\begin{tabular}{|c|c|c|c|c|}
\hline Đau cổ gáy & $\%$ & 20,0 & 16,7 & $>0,05$ \\
\hline $\begin{array}{c}\text { Nôn và buồn } \\
\text { nôn }\end{array}$ & $\%$ & 3,3 & 10,0 & $>0,05$ \\
\hline
\end{tabular}

Nhân xét: Sự khác biệt về các chỉ số đau cổ gáy, nổn và buồn nôn sau điều trị 48 giờ giữa 2 nhóm không có ý nghĩa thống kê.

Số liều Neostigmin+Atropin cân để điều trị: Trong nhóm $\mathrm{N}$, không có bệnh nhân nào cân nhiêuu hơn 2 liều Neostigmin+Atropin để đạt được hiệu quả giảm đau mong muốn. Đa số bệnh nhân cân 2 liêu Neostigmin+Atropin (24 bểnh nhân cần 2 liều điều trị chiếm $80 \%$, 6 bệnh nhân cân 1 liêu điều trị chiếm 20\%).

Số ngày nằm viện: Nhóm $\mathrm{N}$ là 3,90 $\pm 0,92$ ngày, nhóm $P$ là $4,47 \pm 0,78$ ngày, khác biệt có ý nghĩa thống kê $\mathrm{p}<0,05$.

\section{Độ hài lòng của bệnh nhân}

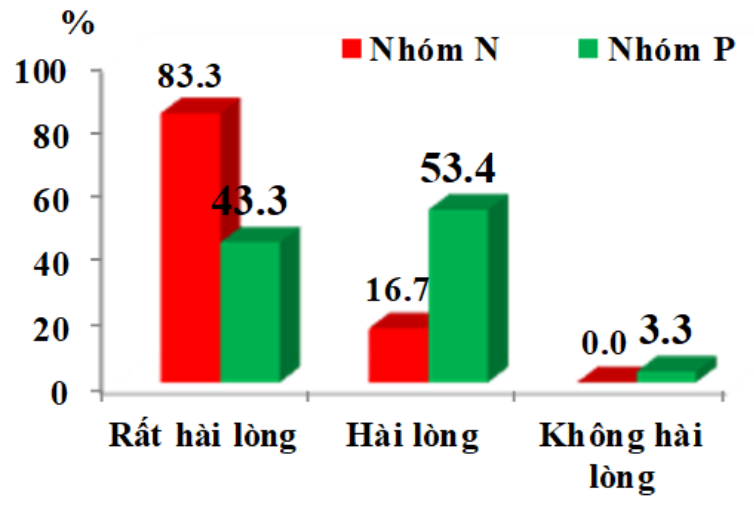

Biểu đồ 2. Độ hài lòng của bệh nhân

Nhân xét: Sự khác biệt về mức độ hài lòng giữa 2 nhóm có ý nghĩa thống kê $(p<0,05)$.

\section{BÀN LUẬN}

Trong nghiên cứu của chúng tôi, 60 sản phụ có độ tuổi từ 21 đến 40 và không có sự khác biệt giữa hai nhóm nghiên cứu. Đây là độ tuổi sinh đẻ của phụ nữ. Tuổi trẻ, nữ, mang thai được xem là yếu tố nguy cơ chính của đau đâu sau thủng màng cứng. [6], [7] Hai nhóm có BMI trung bình tương đương nhau. Tất cả bệnh nhân đều khởi phát đau đâu ở ngày 2 hoặc 3 sau gây tê, phù hợp với các nghiên cứu về đau đâu sau thủng màng cứng đã công bố. [6], [8], [9] Điểm VAS trung bình của nhóm Neostigmin + Atropin thấp hơn đáng kể so với nhóm Paracatamol ở các thời điểm: sau điêu trị 6 giờ, 12 giờ, 24 giờ, 36 giờ, 48 giờ, 72 giờ, khác biệt có ý nghĩa thống kê $(p<0,05)$. Kết quả này phù hợp với nghiên cứu của Abdelaal Ahmed Mahmoud và cộng sự. [5] Điểm VAS trung bình ở nhóm Neostigmin + Atropin trong nghiên cứu của Abdelaal Ahmed Mahmoud $\leq 3$ ở thời điểm 06 giờ sau tiêm sớm 
hơn so với nghiên cứu của chúng tôi (12 giờ sau tiêm). Có thể do điều trị nền trong hai nghiên cứu khác nhau: Trong nghiên cứu của chúng tôi bênh nhân chỉ được điều trị nền bằng tư thế nẳm ngửa, truyền dịch liên tục $30 \mathrm{ml} / \mathrm{kg} / \mathrm{ngày}$ dung dịch Ringerlaclat. Trong nghiên cứu của Abdelaal Ahmed Mahmoud và cộng sự cả hai nhóm đều được điều trị nền bằng tư thế nằm ngửa, truyền liên tục $30 \mathrm{ml} / \mathrm{kg} / \mathrm{ngày}$ dung dịch Ringer lactat, $1 \mathrm{~g}$ paracetamol, $135 \mathrm{mg}$ caffein $/ 6$ giờ, thuốc đạn Ketoprofen $(100 \mathrm{mg})$ hai lần mỗi ngày trong 5 ngày. Kết quả nghiên cứu của chúng tôi cho thấy hiệu quả kiểm soát đau đầu của Neostigmin+Atropin tốt hơn nhiều so với Paracetamol.

Không có bệnh nhân nào nhóm $\mathrm{N}$ cần làm thủ thuật vá máu ngoài màng cứng, trong khi nhóm $\mathrm{P}$ có 6 bệnh nhân $(20 \%), p<0,05$. Kết quả này phù hợp với nghiên cứu của Abdelaal Ahmed Mahmoud: Neostigmin+Atropin sẽ làm giảm tỷ lệ phải thực hiện thủ thuật vá máu ngoài màng cứng. Thủ thuật vá máu ngoài màng cứng ở 6 bệnh nhân nhóm $P$ đều diển ra an toàn, thuận lợi, đạt được hiệu quả sau thực hiện lần đầu, phù hợp với kết quả nghiên cứu về thủ thuật vá máu ngoài màng cứng của Taivainen $T$., Pitkänen M., Tuominen M. và cộng sự [10]. Vá máu ngoài màng cứng là phương pháp điều trị có tỷ lệ thành công khá cao nhưng là phương pháp điều trị xâm lấn và có những nguy cơ cho người bệnh, vì vậy nên được sử dụng làm phương pháp điều trị sau cùng. Neostigmin, Atropin là các thuốc thường được sửu dụng trong gây mê hồi sức là phương pháp điêu trị bảo tồn đơn giản, mang lại hiệu quả khá tốt theo nghiên cứu của chúng tôi, do đó, có thể được sử dụng để điều trị đau đầu sau gây tê tủy sống hoặc gây tê ngoài màng cứng.

Khi dùng liều $20 \mathrm{mcg} / \mathrm{kg}$ Neostigmin và 10 $\mathrm{mcg} / \mathrm{kg}$ Atropin để điều trị đau đâu sau gây tê tủy sônng và gây tê ngoài màng cứng, không làm gia tăng tỷ lệ nôn, buồn nôn sau điều trị. Tỷ lệ bệnh nhân đau cố gáy, nôn, buồn nôn sau điều trị 48 giờ ở 2 nhóm giảm so với trước điều trị, sự khác biệt ở 2 nhóm không có ý nghĩa thống kề $(p>0,05)$. Không có bệnh nhân nào cần nhiều hơn 2 liều Neostigmin + Atropin để đạt được hiệu quả giảm đau mong muốn. Các kết quả này phù hợp với nghiên cứu của Abdelaal Ahmed Mahmoud và cộng sự.

Tình trạng đau đầu được kiểm soát chậm hơn làm cho số ngày nằm viện trung bình của bệnh nhân nhóm $P$ kéo dài hởn nhóm $N$. Mức độ hài lòng phụ thuộc vào hiệu quả giảm đau của phương pháp điều trị cũng như các tác dụng không mong muốn. Sự khác biệt về chỉ số ngày nằm viện và độ hài lòng giữa 2 nhóm có ý nghĩa thống kê $(p<0,05)$. Việc chịu đựng cơn đau đâu kéo dài, khó khăn trong việc cho con bú và phải tốn kinh phí mua thêm 1 bộ catheter ngoài màng cứng cũng như phải chịu thêm một thủ thuật xâm lấn, nằm viện lâu hơn là các yếu tố chính tác động đến tỷ lệ mức độ hài lòng của các bệnh nhân thuộc nhóm P.

\section{KẾT LUẬN}

Qua nghiên cứu chúng tôi thây rằng những sản phụ đau đầu sau gây tê tủy sống hoặc gây tê ngoài màng cứng được điêu trị bằng Neostigmin+Atropin có hiệu quả làm giảm đáng kể điểm VAS khi ngồi thẳng 15 phút, tránh phải thực hiện thủ thuật vá máu ngoài màng cứng, giảm số ngày nằm viện và độ hài lòng cao hơn so với nhóm điều trị bằng Paracetamol.

\section{TÀI LIÊU THAM KHẢO}

1. Guglielminotti J., Landau R., và Li G. (2019). Major Neurologic Complications Associated With Postdural Puncture Headache in Obstetrics: A Retrospective Cohort Study. Anesth Analg, 129(5), 1328-1336.

2. Ghaleb A. (2010). Postdural puncture headache. Anesthesiol Res Pract, 2010, 102967.

3. Kwak K.-H. (2017). Postdural puncture headache. Korean J Anesthesiol, 70(2), 136-143.

4. Plewa M.C. và McAllister R.K. (2021). Postdural Puncture Headache. StatPearls. StatPearls Publishing, Treasure Island (FL).

5. Abdelaal Ahmed Mahmoud A., Mansour A.Z., Yassin H.M. và cộng sứ. (2018). Addition of Neostigmine and Atropine to Conventional Management of Postdural Puncture Headache: A Randomized Controlled Trial. Anesth Analg, 127(6), 1434-1439.

6. Amorim J.A., Gomes de Barros M.V., và Valença M.M. (2012). Post-dural (post-lumbar) puncture headache: risk factors and clinical features. Cephalalgia Int J Headache, 32(12), 916-923.

7. L'ubuský M., Berta E., Procházka M. và cộng sứ. (2006). [Development of incidence of postdural puncture headache in patients undergoing caesarean section in spinal anaesthesia at the Department of Obstetrics and Gynecology in Olomouc during 2003-2004]. Cas Lek Cesk, 145(3), 204-208.

8. Imarengiaye C. và Ekwere I. (2006). Postdural puncture headache: a cross-sectional study of incidence and severity in a new obstetric anaesthesia unit. Afr J Med Med Sci, 35(1), 47-51.

9. Headache Classification Subcommittee of the International Headache Society (2004). The International Classification of Headache Disorders: 2nd edition. Cephalalgia Int J Headache, 24 Suppl 1, 9-160. 